\title{
Processo de educação permanente sob a micropolítica do trabalho vivo em ato de Emerson Merhy: reflexão teórica
}

\author{
Permanent education process under the micropolitics of living work in the act of Emerson Merhy:
} theoretical reflection

Proceso de educación permanente bajo la micropolítica del trabajo vivo en el acto de Emerson Merhy: reflexión teórica

Recebido: 26/12/2020 | Revisado: 26/12/2020 | Aceito: 05/01/2021 | Publicado: 06/01/2021

Gabryella Vencionek Barbosa Rodrigues
ORCID: https://orcid.org/0000-0001-7523-3376
Universidade Federal Fluminense, Brasil
E-mail: vencionek02@ hotmail.com
Elaine Antunes Cortez
Tlune-9648
ORCID: https://orcid.org/0000-0003-3912-9648
Universidade Federal Fluminense, Brasil
E-mail: nanicortez@ hotmail.com
Yasmin Saba de Almeida
ORCID: https://orcid.org/0000-0003-2391-7009
Universidade Federal do Rio Grande do Sul, Brasil
E-mail: yasminsabauff@ gmail.com
Emillia Conceição Gonçalves dos Santos
ORCID: https://orcid.org/0000-0002-5412-7643
Universidade Federal Fluminense, Brasil
E-mail: emilliagsantos@ gmail.com

\begin{abstract}
Resumo
Objetivo: Compreender as confluências da teoria do "trabalho vivo em ato" de Emerson Merhy e o processo de educação permanente em saúde. Metodologia: Reflexão teórica baseada nos conceitos da teoria do "trabalho vivo em ato" de Emerson Merhy em discussão com a Política Nacional de Educação Permanente. Resultados: A vivacidade do trabalho se origina a partir da atividade do trabalhador, no seu exato momento de criação. No campo da Educação Permanente, o trabalho em saúde é centrado no trabalho vivo de forma permanente, já que opera por meio do uso das tecnologias de ação centradas nas relações. A Educação Permanente em Saúde se apresenta como uma ferramenta de gestão efetiva, sendo capaz de trabalhar as realidades e singularidades dos usuários, dos trabalhadores e dos serviços de saúde, por meio da aprendizagem significativa. Considerações finais: As confluências da teoria do "trabalho vivo em ato" de Emerson Merhy e da Política Nacional de Educação Permanente trazem implicações para a prática pedagógica e assistencial em saúde, ao permitir trabalhar uma nova perspectiva durante a reflexão coletiva do processo de trabalho, além de auxiliar na implementação da Educação Permanente nos serviços em saúde.
\end{abstract}

Palavras-chave: Educação Permanente; Trabalho; Saúde; Aprendizagem; Gestão.

\begin{abstract}
Objective: To understand the confluences of the theory of "living work in the act" by Emerson Merhy and the process of permanent health education. Methodology: Theoretical reflection based on the concepts of the theory of "living work in the act" by Emerson Merhy in discussion with the National Policy of Permanent Education. Results: The liveliness of the work originates from the activity of the worker, in his exact moment of creation. In the field of Permanent Education, health work is centered on living work permanently, since it operates through the use of action technologies centered on relationships. Permanent Health Education presents itself as an effective management tool, being able to work with the realities and singularities of users, workers and health services, through meaningful learning. Final considerations: The confluences of Emerson Merhy's theory of "live work in the act" and the National Policy on Permanent Education bring implications for the pedagogical and healthcare practice in health, as it allows to work a new perspective during the collective reflection of the work process, in addition to assisting in the implementation of Permanent Education in health services.
\end{abstract}

Keywords: Education continuing; Work; Health; Learning; Organization and administration.

\section{Resumen}

Objetivo: Comprender las confluencias de la teoría del "trabajo vivo en el acto" de Emerson Merhy y el proceso de educación permanente en salud. Metodología: Reflexión teórica basada en los conceptos de la teoría del "trabajo vivo en el acto" por Emerson Merhy en discusión con la Política Nacional de Educación Permanente. Resultados: La vivacidad del trabajo se origina en la actividad del trabajador, en su momento exacto de creación. En el campo de la 
Educación Permanente, el trabajo de salud se centra en el trabajo vivo de forma permanente, ya que funciona mediante el uso de tecnologías de acción centradas en las relaciones. La Educación Permanente en Salud se presenta como una herramienta de gestión eficaz, capaz de trabajar con las realidades y singularidades de los usuarios, trabajadores y servicios de salud, a través de un aprendizaje significativo. Consideraciones finales: Las confluencias de la teoría de Emerson Merhy sobre el "trabajo vivo en el acto" y la Política Nacional de Educación Permanente tienen implicaciones para la práctica pedagógica y de atención médica en salud, al permitir trabajar desde una nueva perspectiva durante la reflexión colectiva del proceso de trabajo, además de asistir en la implementación de la Educación Permanente en los servicios de salud.

Palabras clave: Educación continua; Trabajo; Salud; Aprendizaje; Organización y administración.

\section{Introdução}

A teoria do "trabalho vivo em ato" de Emerson Merhy, vem sendo difundida desde a década de 1990. Segundo o teórico, "todo processo de trabalho combina trabalho em ato e consumo de produtos feitos em trabalhos anteriores" (Merhy \& Franco, 2008, p. 429), sendo assim, este possui duas dimensões o "trabalho vivo em ato" e o trabalho morto.

Para entender suas definições, faz-se necessário saber sobre as classificações das tecnologias envolvidas no trabalho em saúde. Para Merhy (1997), as tecnologias podem ser classificadas em dura, leve-dura e leve. As leves ou relacionais, referem-se às relações do tipo de produção de vínculo, acolhimento, autonomização e gestão como uma forma de governar processos de trabalho. As leve-duras dizem respeito aos saberes estruturados, que operam no processo de trabalho em saúde, tais como as teorias, a clínica médica, a epidemiologia, o fayolismo e taylorismo. As duras são referentes ao uso de recursos materiais e equipamentos tecnológicos do tipo máquinas, estruturas organizacionais e normas (Coelho \& Jorge, 2009; Grabois, 2011).

Para Merhy e Franco (2008) o "trabalho vivo em ato" se divide em duas perspectivas: uma, é voltada para a atividade realizada, ao qual tem por fundamento construir e vincular uma finalidade a um produto; a outra se vincula ao trabalhador e à sua relação com seu ato produtivo e com os produtos que realiza, assim como suas relações com os outros trabalhadores e com possíveis usuários de seus produtos.

O que confere vida ao trabalho em saúde é o uso das chamadas tecnologias leves, pois permitem trabalhar sob as singularidades e realidades de cada usuário em cada contexto, desta forma, dando sentido para o uso das demais tecnologias (Feuerwerker, 2014).

Mediante a isso, o "trabalho vivo em ato" é aquele que se faz presente no momento de encontro entre duas pessoas, que atuam uma sobre a outra, gerando um jogo de expectativas e produções e, este persiste somente enquanto o momento durar (Merhy \& Franco, 2008; Grabois, 2011).

Já o trabalho morto é aquele que realizado antes, que só ganha destaque através de um produto (Merhy \& Franco, 2008). No território do trabalho morto atuam forças instituídas a partir da conformação dos produtos de momentos anteriores de trabalho vivo. Esses produtos se apresentam, como regra, sob forma de tecnologia dura, que são consumidos pelo processo trabalho vivo (Feuerwerker, 2014). Merhy (2002) ainda destaca que quanto menos criativo e com menor flexibilidade para enfrentar as contingencias impostas pela singularidade, é o trabalho, este se torna menos vivo e, portanto, mais morto.

Dentro do processo de trabalho, cada trabalhador e usuário tem ideias, conceitos e valores sobre a saúde, o trabalho em saúde e como esse deveria ser realizado. Sendo assim, a experiência e a reflexão sobre as práticas profissionais podem gerar no trabalhador uma sensação de desconforto, por meio da ponderação de sua maneira vigente de fazer ou pensar, definindo-a como insuficiente ou insatisfatória para dar conta dos desafios de seu trabalho e assim, ampliando sua disposição para produzir conceitos e práticas alternativas para enfrentar o desafio das transformações no cotidiano de trabalho (Merhy et al., 2006).

Diante disso, a Educação Permanente em Saúde (EPS) constitui-se em um trabalho articulado com vistas a construção da saúde que diz respeito aos usuários e que valoriza os atores sociais do trabalho. Sendo adotada para proporcionar 
reflexão coletiva sobre o processo de trabalho com oferta de instrumento para sua transformação (Brasil, 2014; Portaria $n^{\circ}$ 198/GM, 2004).

A EPS tem por fundamento servir como uma "caixa de ferramentas" que permitiria agir sobre a micropolítica do trabalho em saúde, expandindo os espaços de autonomia dos trabalhadores mediante as práticas e criando espaços coletivos com potencial para construir práticas em saúde comprometidas com os interesses e necessidades dos usuários (Merhy et al., 2006), modulando-a, assim, ao meio e por meio do trabalho vivo em ato.

A motivação para a construção desta reflexão surgiu a partir da observação da existência de fragilidades no processo de trabalho, explicitadas na falta participação e protagonismo dos profissionais em ações educativas.

Assim, esse trabalho se justifica por entender que Emerson Merhy apresenta questões congruentes à Política de Educação Permanente em Saúde, portanto, visa-se, por meio deste, gerar novas possibilidades reflexivas de forma a contribuir para a construção de um novo modo de produzir saúde, pautando-se nas necessidades educacionais dos profissionais a partir do "trabalho vivo em ato", a fim de melhorar o processo de trabalho em saúde.

Logo, o presente artigo tem como objetivo: compreender as confluências da teoria do "trabalho vivo em ato" de Emerson Merhy e o processo de educação permanente em saúde.

\section{Metodologia}

Trata-se de um estudo teórico-reflexivo fundamentado nos conceitos abrangentes à micropolítica do trabalho vivo na saúde, com foco central na teoria do "trabalho vivo em ato" proposto nos estudos de Emerson Merhy (1997, 2002) em discussão com os conceitos da Política Nacional de Educação Permanente.

Esta produção teórica possui natureza exploratória com abordagem qualitativa, devido à interpretação e à análise dos elementos teóricos. Segundo Pereira et al (2018), nesse tipo de abordagem o pesquisador busca interpretar com suas opiniões o fenômeno em estudo.

Para sua fundamentação foi realizado um levantamento bibliográfico, ao qual envolveu leitura, análise e interpretação de livros, dissertações, artigos, leis e publicações governamentais acerca da temática, mesclando-os com intuito de atingir o objetivo da pesquisa, trazer uma maior compreensão e aprofundamento do tema abordado.

\section{Reflexão Teórica}

\section{Processo de trabalho: a micropolítica do trabalho vivo na saúde}

Os conceitos de trabalho vivo e morto começaram a ser difundidos por Karl Marx (1818-1883), quando na parte 1 do seu livro "O Capital", apresenta a relação destes conceitos mediante o processo de trabalho influenciado pelo avanço industrial. O trabalho morto é descrito como o trabalho pregresso, já realizado, estando incorporado aos instrumentos de trabalhos e maquinarias. Já o trabalho vivo é o trabalho em ato, no seu exato momento de criação, se realizando na atividade do trabalhador (Marx, 2017; Franco \& Merhy, 2012).

Mediante a isso, Emerson Merhy, em seus livros "Agir em saúde: um desafio para o público" (1997) e "Saúde: cartografia do trabalho vivo em ato" (2002), este último oriundo da sua tese de livre-docência intitulada de "Reflexões sobre as tecnologias não materiais em saúde e a reestruturação produtiva do setor: uma micropolítica do trabalho vivo", buscou aprofundar os conceitos trazidos por Marx trazendo sua aplicabilidade para o campo da saúde. Para Merhy (1997), ambos conceitos abrangem a chamada "micropolítica do processo de trabalho", dando origem a denominada "micropolítica do trabalho vivo na saúde".

Os serviços de saúde são descritos por Feuerwerkwer (2014, p. 67) como uma "arena em que diversos atores, que se produzem micropoliticamente e tem intencionalidades em suas ações, disputam o sentido geral do trabalho". Estes atores 
atuam de forma a misturar, nem sempre de modo evidente, seus territórios privados de ação e o processo público de trabalho. Portanto, denota-se ao cotidiano múltiplas facetas, e entende-se que esse se encontra em permanente produção (Feuerwerker, 2014).

O trabalho em saúde é um fenômeno sócio-histórico que pode ser entendido como aquele realizado por diversos indivíduos, profissionais e trabalhadores, esses, em sua maioria, com formação na área e caracterizado pelo ato de cuidar, tendo por objetivo atingir a cura, a reabilitação ou a diminuição do sofrimento e, promover o bem-estar. Além disso, este tem sido alvo das mais diversas discussões por sua complexidade e pelas intensas transformações no mundo atual (Sant'Anna \& Hennington, 2011).

Para Merhy (2002), o trabalho em saúde, cuja intencionalidade da ação é marcada pela busca da produção de cuidados voltados a satisfação das necessidades dos usuários, dos trabalhadores ou do serviço, é, por sua vez, centrado no trabalho vivo em ato de forma permanente, possuindo tecnologias de ação configuradas em processos de intervenção em ato, as quais operam como relações, encontros de subjetividade, mantendo-se além dos saberes tecnológicos estruturados (Sant'Anna \& Hennington, 2011).

Os debates acerca do processo de trabalho em saúde, como elemento central do modelo de produção de cuidado, têm sido primordiais para a compreensão de aspectos específicos relacionados ao campo da saúde, reconhecendo, assim, a centralidade do trabalho vivo no processo produtivo do cuidado. Segundo Franco e Merhy (2012, p. 152) nesse processo, "os trabalhadores em atividade atuam sob linhas de força agenciadas por uma ética do cuidado, que se expressam pelo manejo das tecnologias de trabalho e as subjetividades que operam também na produção do mundo do cuidado na saúde". Isso se torna possível, pois o trabalhador autogoverna seu exercício de trabalho, conferindo-o certos graus de liberdade de ação, ainda mais no caso do trabalho em saúde, visto que este é sempre relacional, em ato, nos encontros (Franco \& Merhy, 2012).

Em todo o lugar no qual são produzidas práticas de saúde opera-se o campo dos processos de subjetivação, sendo expressos por meio da construção de territórios de subjetividades comprometidos em produzir certos sentidos para aquelas práticas. "Um modo de produção do cuidado que opera por fluxos de intensidade, mediados pelas tecnologias de trabalho, produz e é produzido também segundo pelos afetos entre os sujeitos" (Feuerwerker, 2014, p. 102), de forma que ao produzirem o mundo do cuidado em saúde, produzem a si mesmos, afetando-se de forma mútua (Merhy, 2005).

No mundo do cuidado, essa afetação mútua ocorre quando os usuários e os trabalhadores se abrem para o encontro, de modo a reconhecer mutuamente como legítimos seus respectivos saberes e expectativas, construindo e negociando de forma compartilhada os projetos de cuidado, que se encontram sempre em disputa (Feuerwerker, 2014). Afinal,

Sem essa referência, pensar o trabalho é quase mover-se cegamente, atado um patamar fixo que pouco explica. É preciso problematizar a questão de que o complexo mundo do trabalho não é um lugar do igual, mas da multiplicidade, do diverso e da diferença, da tensão e da disputa. É importante desmanchar a ideia de um ambiente de trabalho harmônico em si mesmo. Reconhecer a diversidade, os processos de formação das subjetividades, a forma singular de produção do cuidado, trabalho vivo dependente, que revela os afetos, a potência produtiva e a riqueza da práxis (Feuerwerker, 2014, p. 103).

Desta forma, o trabalho em saúde é enigmático e complexo, já que a produção em saúde não existe por si só, sendo necessário que o trabalhador assuma o papel de um verdadeiro arquiteto, utilizando-se de diversas tecnologias de trabalho, normas, instrumentos, conhecimentos, máquinas e agires, dispersos em suas experiências e modos peculiares de cada um operar seu trabalho vivo em ato voltado à produção do cuidado diário (Sant'Anna \& Hennington, 2011). Como o cuidado deve se adequar ao máximo possível as necessidades de cada paciente, faz-se necessário articular as decisões quanto ao uso das tecnologias de trabalho, dos profissionais e do ambiente, em um determinado tempo e espaço (Grabois, 2011). 
Assim, parte-se do pressuposto de que para cuidar dos outros é necessário cuidar de si. Esse processo autoanalítico possui a capacidade de conferir potência para a produção cotidiana do trabalhador, por meio da reflexão das intencionalidades de ação em saúde e do uso correto das tecnologias de trabalho. Portanto, o "olhar pra si" torna-se indispensável para que os trabalhadores possam produzir e espelhar o cuidado de si mesmos, no cuidar dos outros, colocando em análise as suas implicações com a produção da vida. É ao endereçar esse processo autoanalítico ao processo de trabalho que se torna possível adotar a Educação Permanente em Saúde (Feuerwerker, 2014).

\section{A Política Nacional de Educação Permanente em Saúde: a aprendizagem significativa e seu impacto social}

A Política Nacional de Educação Permanente em Saúde (PNEPS) tem como estratégia contribuir ante a necessária transformação dos processos formativos, das práticas pedagógicas e das práticas de condução do sistema e dos serviços de saúde, abarcando também a organização de modelos, processos colegiados e de assessoramento (Brasil, 2014).

A PNEPS foi instruída no ano de 2004 com base no art. 200 da Constituição Federal de 1988, que dispõe a respeito da competência do SUS em prover saúde aos brasileiros, tendo por finalidade adequar a formação e a qualificação dos trabalhadores em saúde às reais necessidades do usuário (Constituição da República Federativa do Brasil, 1988/2020; Fernandes et al., 2017).

Nessa conjuntura, tomou-se como pressuposto a aprendizagem no trabalho, para o trabalho e pelo trabalho, a partir dos desafios enfrentados na realidade dos serviços. Sendo assim, a educação permanente foi adotada nos setores de saúde, visando propiciar a reflexão coletiva sobre o processo de trabalho e ofertar um instrumental para sua transformação (Portaria $n^{\circ}$ 198/GM, 2004).

O conceito de Educação Permanente em Saúde (EPS) é definido, através da portaria GM/MS nº 1996, de 20 de agosto de 2007, que dispõe sobre as diretrizes para implementação da Política Nacional de Educação Permanente em Saúde como sendo: "aprendizagem no trabalho, em que o aprender e o ensinar são incorporados ao cotidiano das organizações e ao processo de trabalho" (Brasil, 2009, p. 20) e propõe que, os processos de educação dos trabalhadores da saúde se façam a partir da problematização da própria prática, além de reafirmar a PNEPS e estabelecer novas estratégias e diretrizes para sua implementação. A Portaria levou em conta as características de cada região, principalmente as necessidades de desenvolvimento e formação para o trabalho de saúde (Brasil, 2009; Portaria $n^{\circ}$ 1.996, 2007).

Com a publicação da PNEPS, a educação permanente ganhou destaque no que se diz respeito ao desenvolvimento dos profissionais para a realidade dos serviços, através da implantação de três dispositivos: a formação de facilitadores de educação permanente, os polos de educação permanente em saúde e a rede de municípios colaboradores, tendo como finalidade a articulação interinstitucional entre os gestores municipais e estaduais, instituições de ensino, docentes e discentes, instâncias de controle social em saúde e serviços de atenção à saúde (Portaria nº 198/GM, 2004).

No processo de educação permanente, o esforço educativo visa explorar a situação de trabalho e educação na saúde, de modo a transformar as situações laborativas em aprendizagem, por meio da análise reflexiva dos problemas da prática (Fernandes et al., 2017; Silva \& Peduzzi, 2011).

Logo, a Educação Permanente é um instrumento extremamente relevante para todos os profissionais, pois esta visa gerar mudanças no processo de trabalho dos setores e assim promover uma melhora nas práticas de saúde ofertadas à população diante da realidade local (Silva et al., 2018; Silva \& Peduzzi, 2011).

No campo da educação permanente, o trabalho em saúde reconhece que a saúde se produz em ato, e suas implicações de que o produto do mesmo só existe enquanto durar o próprio ato de sua produção e para aqueles que estão diretamente envoltos no processo, como os trabalhadores e usuários (Feuerwerker, 2014; Merhy et al., 2006), fundamentando-se, assim, dentro da micropolítica do trabalho vivo em ato. 


\section{Educação Permanente no processo de trabalho a partir da teoria do "trabalho vivo em ato" de Emerson Merhy}

O dia-a-dia do mundo de trabalho em saúde é habitado por vetores pertencentes ao território do trabalho morto e do trabalho vivo, ao quais se encontram e se tencionam a toda ação e a todo encontro. As variadas modalidades de produção do cuidado provocam tensões singulares entre eles, assim como suas próprias composições tecnológicas (Feuerwerker, 2014).

Essa tensão interna ao território do trabalho vivo e a forma como se resolverá como ato produtivo é que dá o tom dos modos de cuidar e que se mostra inseparável do mundo da gestão no campo da política e da organização. E, é nesse lugar que se abre a possibilidade de se construir estratégias de ação do campo da educação permanente, por entendermos que é no mundo do trabalho que a formação efetivamente se concretiza apesar das várias outras modalidades de capacitação que a força de trabalho é submetida (Feuerwerker, 2014, p. 95).

Segundo Merhy et al. (2006) há pelo menos três campos de tensão dentro das organizações de saúde, são eles: o território das práticas em saúde, da produção dos atos em saúde e do terreno das organizações de saúde. Entretanto, um deles se torna mais relevante quando falamos de "trabalho vivo em ato", sendo ele a produção de atos em saúde.

A produção de atos de saúde é o terreno do trabalho vivo, visto que essa é uma área em que se predominam as tecnologias leves (relacionais), em detrimento das tecnologias leves-duras e duras (conhecimento estruturado e equipamentos). O trabalho vivo predomina porque a produção destes atos sempre opera em meio a altos graus de incerteza e com graus não negligenciáveis de autonomia do trabalhador. Essa característica permite a criação de estratégias que possibilitam a construção de novos valores, relações e entendimentos, pois há espaço para a invenção (Merhy et al., 2006).

O trabalho gerado a partir do processo de trabalho em saúde, permite que ocorram diversos encontros. Estes possibilitam a reinvenção e reorganização dos diversos processos de trabalho, em diferentes níveis, portanto, ao seguir essa base a aprendizagem se faz significativa. A partir do momento em que o outro e a suas vivências passam a ser consideradas, cria-se um movimento permanente, movimento esse que se institui como um processo, ao qual pode ocorrer em reuniões informais no âmbito do trabalho, como nos corredores, nas rodas de conversa do café e, que vai acontecendo através da micropolítica do "trabalho vivo em ato" de cada um e de todos (Merhy, 2015; Laprovita, 2017).

No âmbito da EPS, segundo Feuerwerker (2014, p. 97), “o processo de trabalho é tomado como objeto da reflexão participativa e ativa pelos trabalhadores. É a partir da realidade, de suas práticas, das concepções que portam e de suas relações de trabalho que se constroem os processos educativos". Esta autora ainda aponta que ao:

Fazer do mundo do trabalho, na sua micropolítica, um lugar para explicitar estas intencionalidades e implicações, a fim de constituí-los em matéria-prima para a produção de redes de conversas coletivas entre os vários trabalhadores e usuários, que habitam o cotidiano dos serviços e das equipes de saúde, é explorar esta potência inscrita nos fazeres produtivos, como atos pedagógicos (Feuerwerker, 2014, p. 104).

Deste modo, ao se trabalhar e capturar a essência seu trabalho vivo em ato, através da reflexão e autoanalise do seu processo de trabalho, o profissional permite a si mesmo observar os problemas existentes em sua e nas demais práticas ao seu redor, que muitas vezes passariam despercebidos. Assim, abrindo espaço para a inserção de uma estratégia educacional fundamentada e direcionada à uma aprendizagem significativa.

Esse processo de análise do trabalho é fundamental para que o trabalhador possa se converter em coautor da sua própria história. A própria EPS tem como uma de suas finalidades, contribuir para que cada coletivo possa conquistar a capacidade de ser seu próprio coautor por meio de um processo de reinvenção das instituições de saúde e do seu mundo de trabalho em especial (Merhy \& Feuerwerker, 2014).

Portanto, ao tomar como ponto de partida a inserção da EPS como estratégia educativa, reconhecendo a micropolítica do trabalho em saúde, pode-se considerar sua proposta de implementação como uma estratégia de gestão, visto que esta 
permite propiciar um modo operante a gestão em saúde, tomando como foco a produção coletiva de métodos para organizar, micropoliticamente, o cuidado e o trabalho em saúde (Feuerwerker, 2014).

Assim, a EPS permite trabalhar múltiplas possibilidades metodológicas, que vão muito além do processo educacional, permitindo análises e produções coletivas, por parte dos trabalhadores, que podem interferir diretamente no seu processo de trabalho. Logo, ao trabalhar com a alma dos serviços de saúde, a EPS deixa de ser uma simples estratégia de gestão e passa a ser vista, também, como a "alma da gestão" (Merhy \& Feuerwerker, 2014, p. 17).

Deste modo, a Educação Permanente em Saúde seria uma das estratégias para concretizar essa aposta no trabalho vivo e compactuar na construção de pactos ético-políticos que focassem nos usuários e nas suas necessidades na organização do trabalho em saúde (Merhy, 2006; Feuerwerker, 2014).

\section{Considerações Finais}

Com o avanço tecnológico, as mudanças do mercado de trabalho, podem impactar diretamente no resultado e na qualidade da assistência em saúde, mas não somente de forma positiva, já que podem afastar os autores do processo de saúde do uso das tecnologias relacionais durante o processo assistencial.

As tecnologias relacionais estão diretamente correlacionadas com a vivacidade do trabalho, visto que são elas que conferem essa característica ao mesmo, tornando-se presente em seu momento de realização e, criando momentos de tensão necessários para a construção do ato produtivo.

Essa tensão criada entre profissionais e usuários durante o trabalho vivo em ato, permite a observação dos problemas em saúde, dos desafios cotidianos da prática e das lacunas de conhecimento existentes no decorrer do processo de trabalho, estimulando a autorreflexão do trabalhador e da equipe de saúde.

Sendo assim, na busca por soluções, a Educação Permanente em Saúde, se apresenta como uma ferramenta capaz de transformar efetivamente as situações em saúde, ao oferecer a resolução por meio da reflexão coletiva da real problemática e, portanto, fazendo da aprendizagem algo significativo para os trabalhadores e para o serviço em saúde.

Ao se apresentar como instrumento de transformação do processo de trabalho e de modulação das tensões criadas por meio do trabalho vivo em ato, a EPS deixa de ser somente um método de ensino-aprendizagem, atuando como uma tecnologia leve capaz de trabalhar as realidades e singularidades dos usuários em saúde e, ao mesmo tempo, gerenciar micropoliticamente a alma a dos serviços em saúde.

Portanto, a teoria do "trabalho vivo em ato" de Emerson Merhy e a Política Nacional de Educação Permanente, fazem confluências diretas desde sua fundamentação, já que são as tecnologias leves que conferem vida ao trabalho, até seu desfecho, visto que para se produzir saúde, faz-se necessário refletir sobre o real impacto do cuidado nas necessidades dos usuários, dos trabalhadores e dos serviços de saúde e buscar ferramentas capazes de transformar essa realidade por meio de uma aprendizagem realmente significativa. Logo, a EPS se modula ao meio e por meio do trabalho vivo em ato e vice-versa.

Deste modo, a compreensão de suas confluências traz implicações, tanto para a prática pedagógica, quanto para a assistencial, ao apresentar uma nova perspectiva a ser trabalhada e desenvolvida durante a reflexão coletiva do processo de trabalho, além de auxiliar na implementação da Educação Permanente nos serviços em saúde ao trazer uma abordagem mais focada no campo relacional e subjetivo, com uso e destaque às tecnologias leves.

Por se tratar de uma temática inédita, a limitação do estudo está na quantidade escassa de literaturas cientificas que abordassem a Micropolítica do trabalho vivo em ato, a Educação Permanente em Saúde e as suas correlações. Portanto, faz-se necessária a realização de novos estudos sobre a temática visando eliminar essa lacuna no conhecimento científico. 


\section{Referências}

Coelho, M. O., \& Jorge, M. S. B. (2009). Tecnologia das relações como dispositivo do atendimento humanizado na atenção básica à saúde na perspectiva do acesso, do acolhimento e do vínculo. Ciências \& Saúde Coletiva, 14(Supl.1), 1523-1531. http://doi.org/10.1590/S1413-81232009000800026

Constituição da República Federativa do Brasil de 1988 (2020). (56a ed.). Saraiva Jur.

Feuerwerker, L. C. M. (2014). Micropolítica e saúde: produção do cuidado, gestão e formação. Rede UNIDA.

Fernandes, F.C., Cortez, E.A., Laprovita, D., Almeida, L. P., Ferreira, A. F., \& Corvino, M. P. F. (2017). Educação permanente em saúde sob a perspectiva de Agostinho de Hipona. Revista Brasileira de Enfermagem, 70(3), 656-661. https://doi.org/10.1590/0034-7167-2016-0484

Franco, T. B., \& Merhy, E. E. (2012). Cartografia do trabalho e cuidado em saúde. Revista Tempus - Actas de Saúde Coletiva, 6(2), 151-163. 16 de junho de 2020, de http://www.tempus.unb.br/index.php/tempus/article/view/1120

Grabois, V. (2011). Gestão do cuidado. In R. Gondim, V. Grabois, \& W.V. Mendes Junior (Orgs.), Qualificação dos Gestores do SUS (2a ed.), 153-190. Fiocruz/ENSP/EAD.

Laprovita, D. (2017). Núcleo de educação em urgência na lógica da educação permanente: serviço de atendimento pré-hospitalar móvel (Dissertação de Mestrado, Universidade Federal Fluminense). Repositório Institucional da Universidade Federal Fluminense. https://app.uff.br/riuff/handle/1/3110

Merhy, E. E. (1997). Agir em saúde: um desafio para o público. Hucitec.

Merhy, E. E. (2002). Saúde: a cartografia do trabalho vivo em ato. Hucitec.

Merhy, E. E. (2005). Engravidando as palavras: o caso da integralidade. In R. Pinheiro, \& R.A. Mattos (Orgs.). Construção Social da Demanda: direito à saúde, trabalho em equipe, participação e espaços públicos (2a ed.). CEPESC/ UERJ, ABRASCO.

Merhy, E. E. (2015). Educação Permanente em Movimento: uma política de reconhecimento e cooperação, ativando os encontros do cotidiano no mundo do trabalho em saúde, questões para os gestores, trabalhadores e quem mais quiser se ver nisso. Saúde em Redes, 1(1), 7-14. https://doi.org/10.18310/24464813.2015v1n1p07-14

Merhy, E. E., \& Franco, T. B. (2008). Trabalho em saúde. In I. B. Pereira, \& J. C. F. Lima (Orgs.), Dicionário da educação profissional em saúde (2a ed.) 427-432. EPSJV.

Merhy, E. E., \& Feuerwerker, L. C. M. (2014). Educação permanente em saúde: educação, saúde, gestão e produção do cuidado. https://edisciplinas.usp.br/pluginfile.php/4448009/mod_resource/content/1/TRABALHO2.pdf

Merhy, E. E., Feuerwerker, L. C. M., \& Ceccim, R. B. (2006). Educación Permanente en Salud: una Estrategia para Intervenir en la Micropolítica del Trabajo em Salud. Salud Colectiva, 2(2),147-160. https://doi.org/10.18294/sc.2006.62

Marx, K. (2017). O capital: crítica da economia política. O processo de produção do capital (2a ed.). Boitempo.

Ministério da Saúde. (2009). Política Nacional de Educação Permanente em Saúde.

Ministério da Saúde. (2014). Educação permanente em saúde: reconhecer a produção local de cotidianos de saúde e ativar práticas colaborativas de aprendizagem e de entrelaçamento de saberes.

Pereira, A. S., Shitsuka, D. M., Parreira, F. J., \& Shitsuka, R. (2018). Metodologia da pesquisa científica. UFSM.

Portaria nº 198/GM, de 13 de fevereiro de 2004. (2004, 16 fevereiro). Instituí a Política Nacional de Educação Permanente em Saúde como estratégia do Sistema Único de Saúde para a formação e o desenvolvimento de trabalhadores para o setor e dá outras providências. https://www.nescon.medicina.ufmg.br/biblioteca/imagem/1832.pdf

Portaria $n^{\circ}$ 1.996, de 20 de agosto de 2007. (2007, 22 agosto). Dispõe sobre as diretrizes para a implementação da Política Nacional de Educação Permanente em Saúde. http://bvsms.saude.gov.br/bvs/saudelegis/gm/2007/prt1996_20_08_2007.html

Sant'Anna, S. R. S., \& Hennington, E. A. (2011). Micropolítica do trabalho vivo em ato, ergologia e educação popular: proposição de um dispositivo de formação de trabalhadores de saúde. Trabalho, Educação e Saúde, 6(Supl.1), 223-244. https://doi.org/10.1590/S1981-77462011000400011

Silva, A. B., Lopes, G. M., Batista, K. M. P., \& Castro, M. C. S. (2018). A Educação Permanente em Saúde no Serviço de Atendimento Móvel de Urgência. Revista SUSTINERE, 6(1), 63-83. https://doi.org/10.12957/sustinere.2018.31266

Silva, J. A. M., \& Peduzzi, M. (2011). Educação no trabalho na Atenção Primária à Saúde: interfaces entre a educação permanente em saúde e o agir comunicativo. Saúde e Sociedade, 20(4), 1018-1032. https://doi.org/10.1590/S0104-12902011000400018 